\title{
New light on neurotransmitter-gated receptors: Optical approaches for controlling physiological function
}

https://doi.org/10.1515/nf-2017-A049

\begin{abstract}
Neurotransmitter-gated receptors contribute to synaptic transmission and modulation in many ways. Considering glutamate receptors as an example, it becomes clear that these receptor families are highly diverse and that it is experimentally challenging to disentangle the different functional contributions of closely related receptor subtypes. Pharmacological and genetic methods are now complemented by optogenetic approaches, which allow for controlling receptor signaling with light. Using glutamate receptors as an example, I summarize how tethered photoswitchable ligands can be used to control individual receptor subtypes with high spatial and temporal precision, and in specific cells. These, and similarly exciting approaches, offer new possibilities for probing the function of individual receptors in the nervous sys-
\end{abstract} tem.

Keywords: G protein-coupled receptors, glutamate receptors, ligand-gated ion channels, optogenetics, optopharmacology

\section{Introduction}

Our nervous system is a powerful organ of remarkable complexity. Its capabilities arise from an enormous diversity of molecular mechanisms, cell types and connections between specialized brain regions. Cataloging and apprehending this diversity seems key for understanding brain function in health and disease.

Many current experimental efforts are aimed at addressing this diversity on all organizational levels, for instance by defining cell types or mapping connections more precisely, often using sophisticated genetic techniques. Another focus remains on probing the many forms of signal processing that occur within single neurons and

*Corresponding author: Andreas Reiner, Fakultät für Biologie und Biotechnologie, Ruhr-Universität Bochum, Universitätsstraße 150, 44801 Bochum, E-Mail: andreas.reiner@rub.de at individual synapses. For this, it would be desirable to measure or image transmission and signal integration at single synapses, that is in small spine regions $(<1 \mu \mathrm{m})$ and on fast, often millisecond timescales, but also to manipulate these processes with high precision. In this review I summarize the challenges that are associated with studying the role of different receptor subtypes involved in synaptic transmission and modulation, and I describe how the functions of these diverse receptor families might be disentangled by using novel, light-controlled tools. Particular emphasis will be given on light-controlled glutamate receptors (GluRs), but the questions and methodology are applicable to neurotransmitter-gated receptors in general.

\section{Challenges and approaches for studying the physiological function of neurotransmitter-gated receptors}

Studying the molecular events that underlie synaptic transmission, integration, and plasticity has a long history. The actions of chemical neurotransmitters were revealed early, and extensive cloning studies established the molecular identity of the receptors decoding these signals. Indeed, most common neurotransmitters are detected by two receptor classes, i) ionotropic receptors, which are ligand-gated ion channels that primarily facilitate the flow of ions, and ii) metabotropic receptors, which are $\mathrm{G}$ protein-coupled receptors (GPCRs) that control second messenger signaling cascades through $\mathrm{G}$ protein activation. A typical example is glutamate, which is the main excitatory neurotransmitter in the central nervous system of vertebrates and an important neuromodulator, and which is sensed by ionotropic GluRs (iGluRs) and metabotropic GluRs (mGluRs) (Figure 1A). Both receptor families encompass a wide repertoire of subtypes and isoforms with different properties (Monyer et al., 1991; Hollmann and Heinemann, 1994; Traynelis et al., 2010; Reiner and Levitz, 2018). Their functional diversity is further increased by the formation of heteromeric receptors, association with ac- 

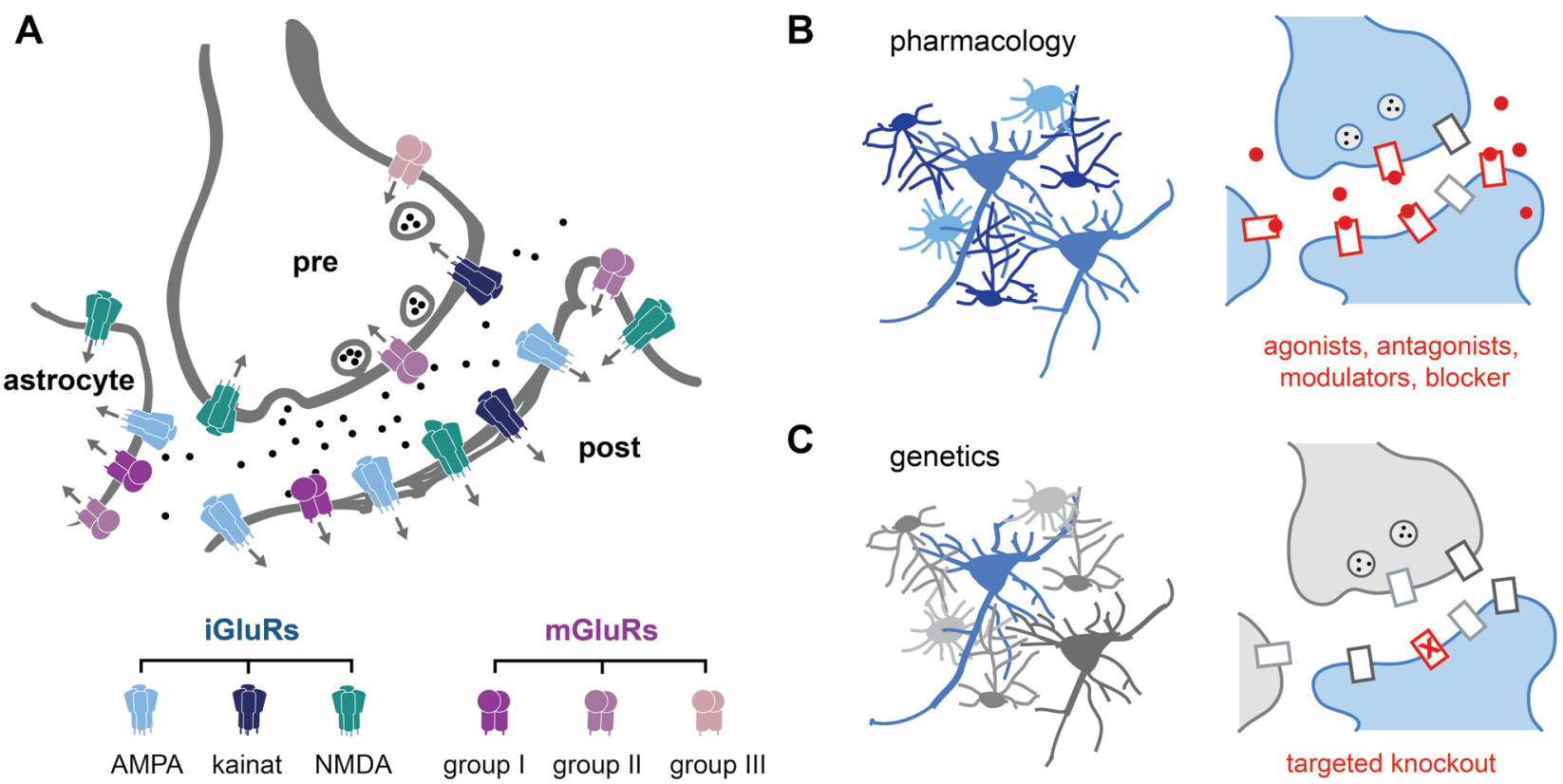

Fig. 1: Neurotransmitter-gated receptors at a glutamatergic synapse and experimental approaches to study them. A: Different ionotropic and metabotropic glutamate receptors, iGluRs (blue/green) and mGluRs (purple), are present in the postsynaptic neuron, but also presynaptically and on glia cells, in this case an astrocyte. It remains challenging to dissect the function of individual GluR subtypes, which contribute to synaptic transmission, homeostasis and plasticity. B: Pharmacological methods may be used to distinguish between different receptor subtypes, but they do not allow to discriminate between different cells and synaptic compartments. C: Genetic methods, e. g. receptor knockouts, provide ultimate specificity, but lack time-resolution.

cessory subunits and scaffolding proteins (Schwenk et al., 2012; Jacobi and von Engelhardt, 2017).

Dissecting the functional roles of the various iGluR and mGluR subtypes is, however, difficult. Many subtypes are widespread in the nervous system and most neurons express several subtypes, which also differs between cellular locations and individual synapses. For instance, iGluRs, which generate postsynaptic excitatory depolarizations, are also found in presynaptic terminals and glia cells, suggesting additional roles in neuromodulation and gliotransmission (Reiner and Levitz, 2018). To make things even more complex, the receptor composition at any given synapse is not static, but subject to change. These adaptations allow for the integration of diverse signals, which forms the basis for synaptic homeostasis as well as plasticity. This complexity is not unique to GluRs, but it is also encountered for many other neurotransmitter-gated receptors. Overall, in most cases we do not know precisely, how individual receptor subtypes contribute to the various physiological processes.

Two main methods have been used for studying the function of neurotransmitter-gated receptors - pharmacological methods and genetic methods (Figure 1B,C). Pharmacological agents, such as agonists, antagonists, allosteric modulators and blockers, allow to interfere with, and to thereby deduce receptor function. For instance, the iGluR agonists AMPA ( $\alpha$-amino-3-hydroxy-5-methyl-4-isoxazolepropionic acid), kainate and NMDA ( $N$-methyl-D-aspartate) were used to define the corresponding iGluR subfamilies. However, despite considerable efforts to develop substances with high subtype selectivity, it remains mostly impossible to activate or inhibit the different iGluR subtypes independently of each other (Traynelis et al., 2010). Moreover, the application of pharmacological agents cannot be used to distinguish between receptors that are present on different cell types or in different synaptic compartments (Figure 1B), e.g. to distinguish between effects that are mediated by activation of pre- or postsynaptic GluRs.

Genetic manipulations provide a complementary approach for studying the role of neurotransmitter-gated receptors, as they allow to abolish, reduce or increase the expression of specific receptor subunits, or to introduce modified receptor subunits (Luo et al., 2018). The genetic manipulation itself is confined to a specific receptor subtype, and it can be performed on selected cells, for instance by relying on specific driver lines, promoters or stereotactic injections (Figure 1C). The large number of transgenic animals and virus tools that has become available makes this a powerful approach. One drawback is that 
genetic manipulations are slow and cannot be turned on or off within the timeframe of most physiological experiments.

\section{Light-based methods and the rise of optogenetics}

Light-based methods offer unique advantages for studying biological systems. Light in the visible range does not interfere with most biological processes and is therefore fairly non-invasive, with red- and near-IR-light penetrating deep into tissue. Maybe more important, light-based methods provide high spatial and temporal resolution compared to pharmacological and genetic manipulations. These advantages are evident from the extensive use of fluorescence-based imaging techniques, which now often include in vivo imaging, two-photon excitation for achieving high optical resolution in tissue, or super-resolution methods to work out details on the tens of nanometer scale.

Light seems not only an ideal tool for observing, but also for manipulating biological processes. A popular approach is photo-uncaging (Ellis-Davies, 2007), which was first applied to second messengers in the mid 1980s and soon after, by George Hess, to acetylcholine and glutamate. In this approach the biologically active compound is "caged" (masked) with a photo-labile protecting group, added in its inactive form to the biological preparation, and released on demand using light. Photo-uncaging allows to release compounds within milliseconds and on the scale of microns, and it became easy to implement with laser light sources being commonly available. Caged agonists for all major neurotransmitter-gated receptors have been developed, as well as some caged-blockers and neuropeptides, often with different optical properties, including efficient two-photon release (Ellis-Davies, 2007; Reiner et al., 2015). One limitation is that photo-uncaging is irreversible, that is the diffusion (or uptake) of the released compound determines, how fast the signal turns off.

An alternative approach, though less commonly used, are photoswitchable neurotransmitter analogues. In this case, the ligand of interest is modified with a photoswitchable group, typically an azobenzene. Azobenzenes undergo a reversible, light-induced trans-to-cis isomerization, which results in a significant conformational change of the ligand thereby modulating its binding affinity to the receptor. Light of certain wavelengths can then be used to switch the ligand back and forth between a high and low affinity configuration. Photo-switchable agonists, antagonists and modulators have now been developed for a wide range of receptors, including iGluRs and mGluRs (Pittolo et al., 2014; Laprell et al., 2015; Barber et al., 2017).

In most cases, photoswitching and photo-uncaging on the timescale of a few milliseconds is sufficiently fast, and the spatial resolution is only limited by ligand diffusion. However, the ligands cannot be targeted to specific cells, which means, for example, that it remains difficult to distinguish between pre- and postsynaptic effects. Nevertheless, caged and switchable ligands have become valuable tools for activating endogenous receptor populations or functional circuit mapping using light.

An important conceptual extension came with the idea to use genetic means to target optical control tools to specific cells (Zemelman and Miesenböck, 2001), a concept which became known as optogenetics (Deisseroth and Hegemann, 2017; Kim et al., 2017; Reiner and Isacoff, 2013). Indeed, an early implementation of this concept was achieved by combining ATP or capsaicin photo-uncaging with the heterologous expression of ATP-gated P2X receptors or capsaicin-sensitive TRP channels in selected cells (Zemelman et al., 2003). Soon after, opsins were recognized as ideal optogenetic tools, in particular for controlling neuronal activity (Boyden et al., 2005; Li et al., 2005; Nagel et al., 2005). The opsin protein family encompasses light-gated GPCRs, e.g. vertebrate rhodopsins, light-driven ion pumps, such as halorhodopsin and bacteriorhodopsin of microbial origin, and, channelrhodopsins, which are light-gated ion channels that were first identified in green algae in 2002 (Nagel et al., 2002). In all opsins the activation is controlled by a light-induced cis-to-trans or trans-to-cis photo-isomerization of a retinal cofactor.

Many opsins are expressed reasonably well in neurons and can therefore be easily combined with state-of-the-art genetic techniques. A particularly popular tool is channelrhodopsin, which can be used to depolarize (activate) selected neurons with short pulses of blue light, and which is now used in a wide range of experimental paradigms, including behavioral studies (Kim et al., 2017). Channelrhodopsin and many other opsins were further engineered to optimize their kinetic and spectral properties, or to alter their ion selectivity (Deisseroth and Hegemann, 2017; Wietek et al., 2017). These tools made light-induced stimulation, and to a lesser extent light-induced silencing (Wiegert et al., 2017) of neurons to standard methods across many fields in neuroscience. 
A

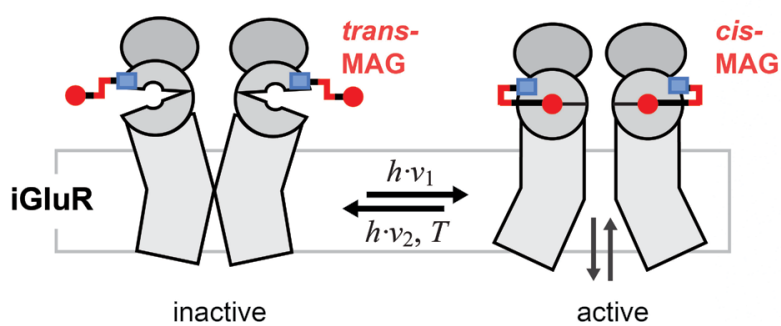

B

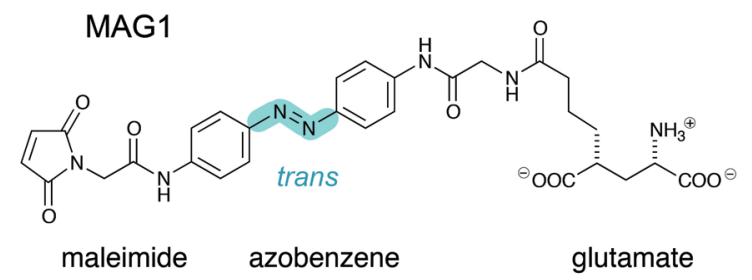

C receptor optogenetics
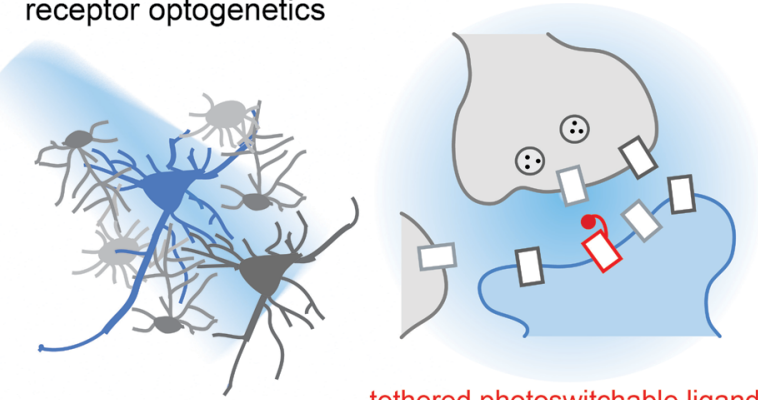

tethered photoswitchable ligands

D

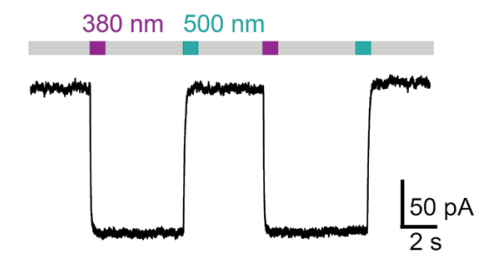

Fig. 2: Tethered photoswitchable ligands allow to control glutamate receptors with light. A: Scheme showing photoswitchable ligands (red) that are covalently attached to genetically modified receptor subunits carrying a cysteine residue (blue) close to the ligand binding pocket. Illumination with light allows to reversible isomerize the ligand and to thereby activate the receptor (photo-agonism). B: Chemical structure of a typical MAG ligand (L-MAG1) that can be isomerized with $375 \mathrm{~nm} / 488 \mathrm{~nm}$ light. Other MAG photoswitches respond to other wavelengths or show a fast spontaneous cis-to-trans relaxation. C: The genetically encoded attachment site makes this approach selective for the chosen receptor subtype and allows targeting to specific cells. D: Example of iGluR photoswitching demonstrated with voltage-clamp recordings. Left, reversible photoswitching of heterologously expressed GluK2(L439C) kainate receptors labeled with a MAG0 photoswitch. Illumination with $380 \mathrm{~nm}$ light (purple bars) yields photo-agonism (inward currents), which can be turned off with $500 \mathrm{~nm}$ light (green bars). Recorded in the presence of a desensitization blocker. Right, fast photoswitching with high intensity light pulses (arrows) yields submillisecond activation and millisecond desensitization kinetics. Panel D was adapted from Reiner and Isacoff, $2014 a$.

\section{Optogenetic control of neurotrans- mitter-gated receptors with pho- toswitchable ligands}

Opsins are ideal tools for controlling neuronal excitability. In parallel, chemo-optogenetic approaches have been developed that allow to light-control proteins that are native to the nervous system (Banghart et al., 2004; Volgraf et al., 2006). One example is the use of tethered photoswitchable ligands, which are covalently coupled to a genetically engineered receptor subunit (Figure 2). This approach has been applied to photo-activate or photo-inhibit iGluRs and mGluRs (Reiner et al., 2015), but has also been transferred to various other receptors (Fehrentz et al., 2011; Kramer et al., 2013).

Tethered photoswitchable ligands are synthetic compounds, which incorporate a functional group that allows to label a receptor of interest at a defined position, a photoswitchable group that elicits a large conformational change upon illumination, and a headgroup that serves as ligand. In the case of GluRs optical activation can be achieved using maleimide-azobenzene-glutamate ligands, also called MAGs (Figure 2A,B) (Volgraf et al., 2006; Gorostiza et al., 2007; Levitz et al., 2013). The maleimide group is used to attach the MAG photoswitch to a genetically encoded cysteine side chain that is introduced in the desired receptor subunit close to the glutamate binding pocket. The azobenzene serves as photoswitch that can be isomerized between its trans and cis configuration using light of different wavelengths, and the glutamate headgroup, a 4-alkylglutamate derivative in L-configuration for iGluRs (D for mGluRs) works as high efficacy agonist.

A major advantage of this approach is that the attachment site on the receptor is genetically encoded. In this way, full subtype specificity is attained, since only receptors containing MAG-labeled subunits will respond to the light stimulus, and targeting to specific cell types and synaptic compartments becomes possible (Figure 2C). The spatial resolution is only limited by the ability to focus light to the region of interest. The temporal resolution is mostly determined by the light intensity, and short, high 
intensity laser pulses can be used to control ligand binding and unbinding on the microsecond and millisecond timescale, respectively (Figure 2D) (Reiner and Isacoff, 2014a). This high temporal resolution allows to mimic various synaptic activation patterns, but also to infer new information on the gating mechanism of iGluRs and mGluRs (Reiner and Isacoff, 2014a; Levitz et al., 2016a).

Light-gated GluRs, such as the photo-activatable kainate receptor variant GluK2, have now been used in a large number of experimental preparations. This includes cultured cells (Reiner and Isacoff, 2014b), primary neuron (Szobota et al., 2007) and astrocyte cultures (Li et al., 2012), brain slices (Berlin et al., 2016), the retina ex vivo and in vivo (Gaub et al., 2014), as well as flies (Kauwe et al., 2013), living zebrafish (Wyart et al., 2009) and mice (Levitz et al., 2016b). In all cases, no side effects were observed and photoswitching was robust and repeatable over extended periods of time. The first generation MAG photoswitches are most efficiently switched with $375 \mathrm{~nm}$ and $488 \mathrm{~nm}$ light. Modifications to the azobenzene switch yielded MAG versions that can be controlled with single pulses of blue light $\left(\mathrm{MAG}_{460}\right.$ ) (Kienzler et al., 2013), or even with red light (Rullo et al., 2014). Some MAG versions are also suitable for two-photon excitation (Carroll et al., 2015). For an overview of the currently available iGluR MAG ligands see Levitz et al., 2016b.

MAG photoswitches have been used to control various iGluR and mGluR subtypes. One recent example is the optical control of different NMDA receptor subunits, which, among other functions, play an important role for postsynaptic $\mathrm{Ca}^{2+}$-signaling and plasticity. Different MAG attachment positions were established to achieve photo-agonism (activation) at GluN2A and GluN2B subunits, but also to achieve photo-antagonism (inhibition) at the GluN2A subunit, or the GluN1 subunit, which is common to all NMDA receptors. In a recent example Berlin, Szobota et al. expressed photo-activatable GluN2A subunits in cultured hippocampal slices (Berlin et al., 2016), where these subunits co-assemble with endogenous GluN1 subunits to form functional NMDA receptor complexes (Figure 3A,B). MAG labeling, followed by light activation of the GluN2A subunits in single dendritic spines allowed to produce local $\mathrm{Ca}^{2+}$-signals, and it was shown that this local activation of postsynaptic GluN2A subunits was sufficient to induce spine swelling, which is indicative of long-term potentiation (Figure 3C,D). The activation of presynaptic NMDA receptors, or any other iGluRs, was apparently not necessary for eliciting this response. Similarly, the use of photo-antagonistic versions revealed that partially inhibiting postsynaptic GluN1/GluN2A receptors is sufficient to suppress spine swelling and induction of long-term potentiation at hippocampal CA3-CA1 synapses.
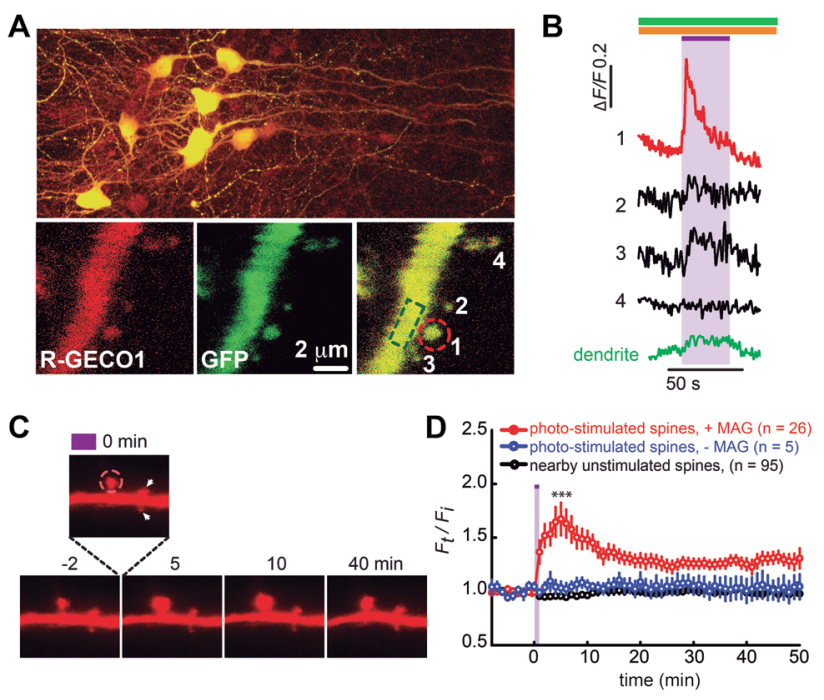

Fig. 3: Photo-activation of postsynaptic, GluN2A-containing NMDA receptors elicits $\mathrm{Ca}^{2+}$-influx and spine swelling. A: Organotypic hippocampal slice with CA1 neurons expressing the red fluorescent $\mathrm{Ca}^{2+}$-sensor R-GECO1 (red), GFP (green), and the photo-activatable NMDA receptor subunit GluN2A(V713C). B: Upon MAG labeling and transient photo-activation of the GluN2A(V713C) subunit with $405 \mathrm{~nm}$ light, a pronounced $\mathrm{Ca}^{2+}$-influx (increase in R-GECO1 fluorescence) is observed in the targeted spine (region 1), but not in the neighboring spines (region 2-4), and only weakly in the dendrite. C: Expansion of a single spine observed after MAG-GluN2A(V713C) photo-activation for 1-2 $\min (t=0)$, visualized by co-expression of red-fluorescent tdTomato. D: Spine expansion is triggered by photoactivation, but not in neighboring spines nor in control conditions. After an initial swelling, spines stayed enlarged for at least $45 \mathrm{~min}$. The figure was adapted from Berlin et al., 2016.

The success of this concept has triggered interest in alternative labeling schemes and for mGluRs a SNAP-based approach was implemented recently (Broichhagen et al., 2015). In this approach an extracellular SNAP domain is fused to the receptor of interest, which then can be labeled with a benzylguanine-azobenzene-glutamate (BGAG) photoswitch. SNAP-labeling provides higher specificity compared to cysteine labeling, requires lower ligand concentrations, and is potentially easier to transfer between different receptor subunits. A combination of SNAP- and CLIP-labeling can be even used to control two different receptor populations within the same preparation (Levitz et al., 2017). Alternatively, affinity labeling schemes have been developed, which lack genetic encoding but allow for targeting endogenous receptor populations (Izquierdo-Serra et al., 2016). 
Chemo-optogenetic approaches are not limited to GluRs, but similar tethered photoswitchable ligands have been developed for numerous other receptor families, including nicotinic acetylcholine receptors (Tochitsky et al.,

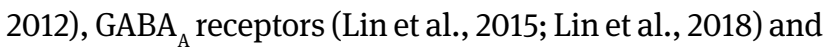
dopamine receptors (Donthamsetti et al., 2017). Similarly, photoswitchable tethered pore blockers have been used to manipulate various potassium channel families (Banghart et al., 2004; Sandoz and Levitz, 2013). Furthermore, azobenzene photoswitches have been used to control receptor function allosterically, e.g. in the case of the purine-sensitive P2X receptors, where they were placed to bridge the pore region (Browne et al., 2014; Habermacher et al., 2016), or in the case of NMDA receptors, where photoswitchable azobenzene amino acids were incorporated by stop codon suppression (Klippenstein et al., 2017). Other non-natural, photo-sensitive amino acids have been used for selective receptor inactivation (Klippenstein et al., 2014).

\section{Other strategies for controlling synaptic signaling proteins with light}

Numerous other optogenetic approaches have been developed, which can be of use to manipulate synaptic signaling processes. An early and important example is the control of neuronal second messenger signaling by using vertebrate rhodopsin, a light-activated GPCR that, through $\mathrm{G}_{\mathrm{i} / \mathrm{o}}$ activation, inhibits voltage-gated calcium channels and activates GIRK (potassium) channels (Li et al., 2005). Furthermore, rhodopsins have been used to emulate ligand-gated GPCRs by constructing chimeras, which carry the intracellular regions that determine their signaling and trafficking properties. This was first demonstrated by creating a chimera of rhodopsin and a beta-2 adrenergic receptor (Kim et al., 2005), and similar chimeras were later developed to work in the nervous system, named opto-XRs (Airan et al., 2009). A similar strategy was used to construct a light-gated GPCR mimicking a serotonin receptor (5- $\left.\mathrm{HT}_{1 \mathrm{~A}}\right)$ (Oh et al., 2010), and has now been extended to other serotonin receptor subtypes and using cone opsins and melanopsins as alternative scaffolds (Masseck et al., 2014; Spoida et al., 2014). Recently, this approach has also been utilized to investigate the signaling properties of orphan GPCRs for which no ligand has yet been described (Morri et al., 2018).

Other optogenetic approaches rely on light-sensitive protein domains to control cellular processes, many of them using LOV domains or phytochromes to induce large conformational changes, or to control protein association or localization (Möglich and Moffat, 2010). Examples include optogenetic tools to control transcription, vesicle trafficking (van Bergeijk et al., 2015), scaffolding (Sinnen et al., 2017), protein aggregation (Lee et al., 2014), inactivation and degradation, all of which could be applied to study receptor-mediated signaling.

\section{Outlook}

Combining genetics with optical techniques may help us to overcome some of the long-standing experimental challenges associated with studying the molecular mechanisms of synaptic signaling. For instance: The ability to target receptors in specific synaptic compartments should be well suited to study neuron-glia interactions. The high temporal precision should make it possible to probe the consequences of different activation patterns, e.g. on short timescales relevant to spike-timing-dependent plasticity, or, on long developmental timescales. The ability to address individual receptor subtypes should be of use to decipher their specific functions, but also to study the crosstalk between closely related receptors (Reiner and Levitz, 2018). Moreover, the possibility of performing these manipulations in distinct neuronal populations in vivo may help defining more precisely, which receptor subtypes and brain regions should be targeted for therapeutic interventions. Developing and using these techniques should thus yield exciting and new insights - starting at individual synapses, over circuit function to cognition and behavior.

Article note: German version available at https://doi.org/10.1515/nf2017-0049

\section{References}

Airan, R.D., Thompson, K.R., Fenno, L.E., Bernstein, H., and Deisseroth, K. (2009). Temporally precise in vivo control of intracellular signalling. Nature 458, 1025-1029.

Banghart, M., Borges, K., Isacoff, E., Trauner, D., and Kramer, R.H. (2004). Light-activated ion channels for remote control of neuronal firing. Nat. Neurosci. 7, 1381-1386.

Barber, D.M., Liu, S.A., Gottschling, K., Sumser, M., Hollmann, M., and Trauner, D. (2017). Optical control of AMPA receptors using a photoswitchable quinoxaline-2,3-dione antagonist. Chem. Sci. 8, 611-615.

Berlin, S., Szobota, S., Reiner, A., Carroll, E.C., Kienzler, M.A., Guyon, A., Xiao, T., Trauner, D., and Isacoff, E.Y. (2016). A family of photoswitchable NMDA receptors. eLife 5, e12040. 
Boyden, E.S., Zhang, F., Bamberg, E., Nagel, G., and Deisseroth, K. (2005). Millisecond-timescale, genetically targeted optical control of neural activity. Nat. Neurosci. 8, 1263-1268.

Broichhagen, J., Damijonaitis, A., Levitz, J., Sokol, K.R., Leippe, P., Konrad, D., Isacoff, E.Y., and Trauner, D. (2015). Orthogonal optical control of a $\mathrm{G}$ protein-coupled receptor with a SNAP-tethered photochromic ligand. ACS Cent. Sci. 1, 383-393.

Browne, L.E., Nunes, J.P., Sim, J.A., Chudasama, V., Bragg, L., Caddick, S., and North, R.A. (2014). Optical control of trimeric $\mathrm{P} 2 \mathrm{X}$ receptors and acid-sensing ion channels. Proc. Natl. Acad. Sci. USA 111, 521-526.

Carroll, E.C., Berlin, S., Levitz, J., Kienzler, M.A., Yuan, Z., Madsen, D., Larsen, D.S., and Isacoff, E.Y. (2015). Two-photon brightness of azobenzene photoswitches designed for glutamate receptor optogenetics. Proc. Natl. Acad. Sci. USA 112, E776-785.

Deisseroth, K., and Hegemann, P. (2017). The form and function of channelrhodopsin. Science 357, eaan5544.

Donthamsetti, P.C., Winter, N., Schönberger, M., Levitz, J., Stanley, C., Javitch, J.A., Isacoff, E.Y., and Trauner, D. (2017). Optical control of dopamine receptors using a photoswitchable tethered inverse agonist. J. Am. Chem. Soc. 139, 18522-18535.

Ellis-Davies, G.C. (2007). Caged compounds: photorelease technology for control of cellular chemistry and physiology. Nat. Methods 4, 619-628.

Fehrentz, T., Schönberger, M., and Trauner, D. (2011). Optochemical genetics. Angew. Chem. Int. Ed. Engl. 50, 12156-12182.

Gaub, B.M., Berry, M.H., Holt, A.E., Reiner, A., Kienzler, M.A., Dolgova, N., Nikonov, S., Aguirre, G.D., Beltran, W.A., Flannery, J.G., and Isacoff, E.Y. (2014). Restoration of visual function by expression of a light-gated mammalian ion channel in retinal ganglion cells or ON-bipolar cells. Proc. Natl. Acad. Sci. USA 111, E5574-5583.

Gorostiza, P., Volgraf, M., Numano, R., Szobota, S., Trauner, D., and Isacoff, E.Y. (2007). Mechanisms of photoswitch conjugation and light activation of an ionotropic glutamate receptor. Proc. Natl. Acad. Sci. USA 104, 10865-10870.

Habermacher, C., Martz, A., Calimet, N., Lemoine, D., Peverini, L., Specht, A., Cecchini, M., and Grutter, T. (2016).

Photo-switchable tweezers illuminate pore-opening motions of an ATP-gated P2X ion channel. eLife 5, e11050.

Hollmann, M., and Heinemann, S. (1994). Cloned glutamate receptors. Annu. Rev. Neurosci. 17, 31-108.

Jacobi, E., and von Engelhardt, J. (2017). Diversity in AMPA receptor complexes in the brain. Curr. Opin. Neurobiol. 45, 32-38.

Izquierdo-Serra, M., Bautista-Barrufet, A., Trapero, A., GarridoCharles, A., Díaz-Tahoces, A., Camarero, N., Pittolo, S., Valbuena, S., Pérez-Jiménez, A., Gay, M., et al. (2016). Optical control of endogenous receptors and cellular excitability using targeted covalent photoswitches. Nat. Commun. 7, 12221.

Kauwe, G., and Isacoff, E.Y. (2013). Rapid feedback regulation of synaptic efficacy during high-frequency activity at the Drosophila larval neuromuscular junction. Proc. Natl. Acad. Sci. USA 110, 9142-9147.

Kienzler, M.A., Reiner, A., Trautman, E., Yoo, S., Trauner, D., and Isacoff, E.Y. (2013). A red-shifted, fast-relaxing azobenzene photoswitch for visible light control of an ionotropic glutamate receptor. J. Am. Chem. Soc. 135, 17683-17686.

Kim, J.M., Hwa, J., Garriga, P., Reeves, P.J., RajBhandary, U.L., and Khorana, H.G. (2005). Light-driven activation of beta 2-adrenergic receptor signaling by a chimeric rhodopsin containing the beta 2-adrenergic receptor cytoplasmic loops. Biochemistry 44, 2284-2292.

Kim, C.K., Adhikari, A., and Deisseroth, K. (2017). Integration of optogenetics with complementary methodologies in systems neuroscience. Nat. Rev. Neurosci. 18, 222-235.

Klippenstein, V., Ghisi, V., Wietstruk, M., and Plested, A.J. (2014). Photoinactivation of glutamate receptors by genetically encoded unnatural amino acids. J. Neurosci. 34, 980-991.

Klippenstein, V., Hoppmann, C., Ye, S., Wang, L., and Paoletti, P. (2017). Optocontrol of glutamate receptor activity by single side-chain photoisomerization. eLife 6, e25808.

Kramer, R.H., Mourot, A., and Adesnik, H. (2013). Optogenetic pharmacology for control of native neuronal signaling proteins. Nat. Neurosci. 16, 816-823.

Laprell, L., Repak, E., Franckevicius, V., Hartrampf, F., Terhag, J., Hollmann, M., Sumser, M., Rebola, N., DiGregorio, D.A., and Trauner, D. (2015). Optical control of NMDA receptors with a diffusible photoswitch. Nat. Commun. 6, 8076.

Lee, S., Park, H., Kyung, T., Kim, N.Y., Kim, S., Kim, J., and Heo, W.D. (2014). Reversible protein inactivation by optogenetic trapping in cells. Nat. Methods 11, 633-636.

Levitz, J., Pantoja, C., Gaub, B., Janovjak, H., Reiner, A., Hoagland, A., Schoppik, D., Kane, B., Stawski, P., Schier, A.F., et al. (2013). Optical control of metabotropic glutamate receptors. Nat. Neurosci. 16, 507-516.

Levitz, J., Habrian, C., Bharill, S., Fu, Z., Vafabakhsh, R., and Isacoff, E.Y. (2016a). Mechanism of assembly and cooperativity of homomeric and heteromeric metabotropic glutamate receptors. Neuron 92, 143-159.

Levitz, J., Popescu, A.T., Reiner, A., and Isacoff, E.Y. (2016b). A toolkit for orthogonal and in vivo optical manipulation of ionotropic glutamate receptors. Front. Mol. Neurosci. 9, 2.

Levitz, J., Broichhagen, J., Leippe, P., Konrad, D., Trauner, D., and Isacoff, E.Y. (2017). Dual optical control and mechanistic insights into photoswitchable group II and III metabotropic glutamate receptors. Proc. Natl. Acad. Sci. USA 114, E3546-3554.

Li, X., Gutierrez, D.V., Hanson, M.G., Han, J., Mark, M.D., Chiel, H., Hegemann, P., Landmesser, L.T., and Herlitze, S. (2005). Fast noninvasive activation and inhibition of neural and network activity by vertebrate rhodopsin and green algae channelrhodopsin. Proc. Natl. Acad. Sci. USA 102, 17816-17821.

Li, D., Hérault, K., Isacoff, E.Y., Oheim, M., and Ropert, N. (2012). Optogenetic activation of LiGluR-expressing astrocytes evokes anion channel-mediated glutamate release. J. Physiol. 590, 855-873.

Lin, W.C., Tsai, M.C., Davenport, C.M., Smith, C.M., Veit, J., Wilson, N.M., Adesnik, H., and Kramer, R.H. (2015). A Comprehensive optogenetic pharmacology toolkit for in vivo control of GABA(A) receptors and synaptic inhibition. Neuron $88,879-891$.

Lin, W.C., Tsai, M.C., Rajappa, R., and Kramer, R.H. (2018). Design of a highly bistable photoswitchable tethered ligand for rapid and sustained manipulation of neurotransmission. J. Am. Chem. Soc. 140, 7445-7448.

Luo, L., Callaway, E.M., and Svoboda, K. (2018). Genetic dissection of neural circuits: A decade of progress. Neuron 98, 256-281.

Masseck, O.A., Spoida, K., Dalkara, D., Maejima, T., Rubelowski, J.M., Wallhorn, L., Deneris, E.S., and Herlitze, S. (2014). Vertebrate cone opsins enable sustained and highly sensitive 
rapid control of Gi/o signaling in anxiety circuitry. Neuron 81 , 1263-1273.

Monyer, H., Seeburg, P.H., and Wisden, W. (1991). Glutamateoperated channels: developmentally early and mature forms arise by alternative splicing. Neuron 6, 799-810.

Morri, M., Sanchez-Romero, I., Tichy, A.M., Kainrath, S., Gerrard, E.J., Hirschfeld, P.P., Schwarz, J., and Janovjak, H. (2018). Optical functionalization of human Class A orphan G-proteincoupled receptors. Nat. Commun. 9, 1950.

Möglich, A., and Moffat, K. (2010). Engineered photoreceptors as novel optogenetic tools. Photochem. Photobiol. Sci. 9, $1286-1300$

Nagel, G., Ollig, D., Fuhrmann, M., Kateriya, S., Musti, A.M., Bamberg, E., and Hegemann, P. (2002). Channelrhodopsin-1: a light-gated proton channel in green algae. Science 296, 2395-2398.

Nagel, G., Brauner, M., Liewald, J.F., Adeishvili, N., Bamberg, E., and Gottschalk, A. (2005). Light activation of channelrhodopsin-2 in excitable cells of Caenorhabditis elegans triggers rapid behavioral responses. Curr. Biol. 15, 2279-2284.

Oh, E., Maejima, T., Liu, C., Deneris, E., and Herlitze, S. (2010). Substitution of 5-HT1A receptor signaling by a light-activated G protein-coupled receptor. J. Biol. Chem. 285, 30825-30836.

Pittolo, S., Gómez-Santacana, X., Eckelt, K., Rovira, X., Dalton, J., Goudet, C., Pin, J.P., Llobet, A., Giraldo, J., Llebaria, A., and Gorostiza, P. (2014). An allosteric modulator to control endogenous $G$ protein-coupled receptors with light. Nat. Chem. Biol. 10, 813-815.

Reiner, A., and Isacoff, E.Y. (2013). The Brain Prize 2013: The optogenetics revolution. Trends Neurosci. 36, 557-560.

Reiner, A., and Isacoff, E.Y. (2014a). Tethered ligands reveal glutamate receptor desensitization depends on subunit occupancy. Nat. Chem. Biol. 10, 273-280.

Reiner, A., and Isacoff, E.Y. (2014b). Photoswitching of cell surface receptors using tethered ligands. Methods Mol. Biol. 1148, 45-68.

Reiner, A., Levitz, J., and Isacoff, E.Y. (2015). Controlling ionotropic and metabotropic glutamate receptors with light: principles and potential. Curr. Opin. Pharmacol. 20,135-143.

Reiner, A., and Levitz, J. (2018). Glutamatergic signaling in the central nervous system: Ionotropic and metabotropic receptors in concert. Neuron 98, 1080-1089.

Rullo, A., Reiner, A., Reiter, A., Trauner, D., Isacoff, E.Y., and Woolley, G.A. (2014). Long wavelength optical control of glutamate receptor ion channels using a tetra-ortho-substituted azobenzene derivative. Chem. Commun. 50, 14613-14615.

Sandoz, G., and Levitz, J. (2013). Optogenetic techniques for the study of native potassium channels. Front. Mol. Neurosci. 6, 6 .

Schwenk, J., Harmel, N., Brechet, A., Zolles, G., Berkefeld, H., M.ller, C.S., Bildl, W., Baehrens, D., H,ber, B., Kulik, A., et al. (2012). High-resolution proteomics unravel architecture and molecular diversity of native AMPA receptor complexes. Neuron 74, 621-633.

Sinnen, B.L., Bowen, A.B., Forte, J.S., Hiester, B.G., Crosby, K.C., Gibson, E.S., Dell'Acqua, M.L., and Kennedy, M.J. (2017). Optogenetic control of synaptic composition and function. Neuron 93, 646-660.

Spoida, K., Masseck, O.A., Deneris, E.S., and Herlitze, S. (2014). $\mathrm{Gq} / 5-\mathrm{HT} 2 \mathrm{c}$ receptor signals activate a local GABAergic

inhibitory feedback circuit to modulate serotonergic firing and anxiety in mice. Proc. Natl. Acad. Sci. USA 111, 64796484.

Szobota, S., Gorostiza, P., Del Bene, F., Wyart, C., Fortin, D.L., Kolstad, K.D., Tulyathan, O., Volgraf, M., Numano, R., Aaron, H.L., et al. (2007). Remote control of neuronal activity with a light-gated glutamate receptor. Neuron 54, 535-545.

Tochitsky, I., Banghart, M.R., Mourot, A., Yao, J.Z., Gaub, B., Kramer, R.H., and Trauner, D. (2012). Optochemical control of genetically engineered neuronal nicotinic acetylcholine receptors. Nat. Chem. 4, 105-111.

Traynelis, S.F., Wollmuth, L.P., McBain, C.J., Menniti, F.S., Vance, K.M., Ogden, K.K., Hansen, K.B., Yuan, H., Myers, S.J., and Dingledine, R. (2010). Glutamate receptor ion channels: structure, regulation, and function. Pharmacol. Rev. 62, 405-496.

van Bergeijk, P., Adrian, M., Hoogenraad, C.C., and Kapitein, L.C. (2015). Optogenetic control of organelle transport and positioning. Nature 518, 111-114.

Volgraf, M., Gorostiza, P., Numano, R., Kramer, R.H., Isacoff, E.Y., and Trauner, D. (2006). Allosteric control of an ionotropic glutamate receptor with an optical switch. Nat. Chem. Biol. 2, 47-52.

Wietek, J., Rodriguez-Rozada, S., Tutas, J., Tenedini, F., Grimm, C., Oertner, T.G., Soba, P., Hegemann, P., and Wiegert, J.S. (2017). Anion-conducting channelrhodopsins with tuned spectra and modified kinetics engineered for optogenetic manipulation of behavior. Sci. Rep. 7, 14957.

Wiegert, J.S., Mahn, M., Prigge, M., Printz, Y., and Yizhar, O. (2017). Silencing neurons: Tools, applications, and experimental constraints. Neuron 95, 504-529.

Wyart, C., Del Bene, F., Warp, E., Scott, E.K., Trauner, D., Baier, H., and Isacoff, E.Y. (2009). Optogenetic dissection of a behavioural module in the vertebrate spinal cord. Nature 461, 407-410.

Zemelman, B.V., and Miesenböck, G. (2001). Genetic schemes and schemata in neurophysiology. Curr. Opin. Neurobiol. 11, 409-414.

Zemelman, B.V., Nesnas, N., Lee, G.A., and Miesenböck, G. (2003). Photochemical gating of heterologous ion channels: remote control over genetically designated populations of neurons. Proc. Natl. Acad. Sci. USA 100, 1352-1357.

\section{Glossary}

\author{
$5-\mathrm{HT}_{1 \mathrm{~A}}$ receptor
}

AMPA receptors

azobenzene

BGAG photoswitch serotonin (5-hydroxytryptamine) receptor $1 \mathrm{~A}$ (G-coupled GPCR)

iGluR subfamily, named after their agonist $\alpha$-amino-3-hydroxy-5-methyl-4isoxazolepropionic acid a chemical group, which is often used as a photoswitch since it undergoes a light-induced trans-cis / cis-trans isomerization benzylguanine-azobenzene-glutamate photoswitch for the optical control of iGluRs (for attachment to SNAP tags) 
$\mathrm{GABA}_{\mathrm{A}}$ receptor

GIRK channels

GluK2

GluNx

GPCR

iGluR

LOV domains

MAG photoswitch

$\mathrm{\gamma}$-aminobutyric acid receptor A (ligand-gated chloride channel)

$\mathrm{G}$ protein-coupled inwardly-rectifying potassium channels

kainate receptor subunit 2 (formerly iGluR6)

NMDA receptor subunits

$\mathrm{G}$ protein-coupled receptor

ionotropic glutamate receptor (ligand-gated ion channel)

light-oxygen-voltage-sensing domains, a

family of flavin-containing protein domains, which change their conformation upon illumination

maleimide-azobenzene-glutamate photoswitch for the optical control of iGluRs (for attachment to cysteine residues)

\section{Bionotes}

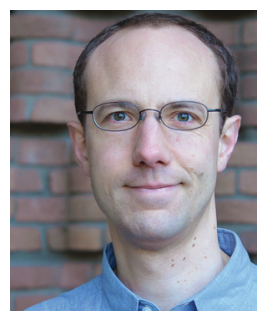

\section{Andreas Reiner}

Fakultät für Biologie und Biotechnologie, Ruhr-Universität Bochum

Universitätsstraße 150

44801 Bochum

E-Mail: andreas.reiner@rub.de

Andreas Reiner is Juniorprofessor and leads the research group "Cellular Neurobiology" at the Ruhr-University Bochum, Germany. He studied Biochemistry at the University of Bayreuth, Germany and obtained his PhD working with Thomas Kiefhaber at the Biozentrum Basel, Switzerland. After a research stay at the Technical University Munich, he joined the lab of Ehud Y. Isacoff at the University of California Berkeley, where he started studying neuronal glutamate receptors using optochemical approaches. In 2015 he was awarded with a stipend from the NRW Rückkehrerprogramm. His research focus is on using and developing optical approaches to address novel mechanistic and physiological aspects of glutamate receptor function.
mGluR

NMDA receptors

P2X receptors

SNAP/CLIP tags

TRP channels metabotropic glutamate receptor (GPCR)

iGluR subfamily, named after their agonist $\mathrm{N}$-methyl-D-aspartate

ionotropic purinergic receptors (ATP-gated cation channels)

protein tags, which react with $O^{6}$-benzylguanine derivatives (SNAP) and $O^{2}$-benzylcytosine derivatives (CLIP), respectively, and which can be used for covalent attachment of dyes or photoswitches transient receptor potential channels, a class of cation channels, some of which can be activated by ligands 